\title{
Solar energy: a common-sense vision
}

\section{David Samuel Ginley* and Philip Anthony Parilla}

National Renewable Energy Laboratory, Golden, CO, USA

*Correspondence: david.ginley@nrel.gov

Edited by:

Avner Rothschild, Technion - Israel Institute of Technology, Israel

Keywords: solar energy, energy, sustainability, electricity, energy storage

The sun (Sol) is, by far, the dominant energy source in our solar system, and therefore, for the planet Earth and its 7.1 billion people (U. S. C. Bureau, 2013). But it is much more than that to all of humanity and the 8.7 million diverse species (Mora et al., 2011) that inhabit the Earth; it is the basis for sustaining all life on this planet and it gives us warmth and comfort. It is the "engine" of the Earth's ecosystem, supplying heat to drive the climate and weather; helping to form niches where evolution has created the vast and interconnected biosphere, its diversity critical to the sustainability of life. Without the sun, the earth would be a lifeless frozen rock (perhaps with the exception of a few extremophile life forms $)^{1}$. With the sun, the earth maintains a steady-state balance with the sun's incoming energy that allows temperatures high enough for water to be liquid across most of the planet and life to flourish. Within the cross-section that the Earth's size represents, sunlight delivers $\sim 174 \mathrm{PW}\left(10^{15} \mathrm{~W}\right)$ of power (Rhodes, 2010; Tian and Zhao, 2013), while in comparison, the worldwide rate of consumption for industrial types of energy averages $\sim 16 \mathrm{TW}$, a factor $\sim 10,000$ times smaller (Rhodes, 2010). From this perspective, given its abundance and availability, humans would be wise to predominantly use the energy from the sun. And we do ... in a manner. However, it is not the direct and immediate conversion of sunlight, which would be more desirable and sustainable. Instead, we have discovered that the transformed remains of dead plants and animals have a high chemical-energy content in the form of hydrocarbons originally derived, directly or indirectly, from sunlight. Photosynthesis was Nature's first successful attempt at actively harvesting the

${ }^{1}$ Although it is possible that the sun's energy was a critical component for abiogenesis to occur. energy of the sun. It supports the entire food chain; it has enriched the Earth's atmosphere with oxygen; and subsequently provided the biomass produced in conjunction with heat, pressure, and immense time to yield the predominant energy sources that we humans use today. And use it, we do, to the effect of introducing $\sim 32$ billion metric tons of carbon dioxide per year (Boden et al., 2012) into the atmosphere from fossil fuels and with the result that the carbon dioxide atmospheric concentration has surpassed $400 \mathrm{ppm}$ for the first time ever at the Mauna Loa monitoring station (May, 2013) (Tans and Keeling, 2013) and is much higher than the previous maxima ( $-300 \mathrm{ppm})$ determined over the last 800,000 years! (Lüthi et al., 2008a,b). This increasing $\mathrm{CO}_{2}$ concentration is generally accepted to be the primary cause for the global rise in temperatures, commonly known as the "greenhouse effect." This has subsequently destabilized the overall climate and put ever increasing pressures on finding sustainable energy solutions
(IPCC, 2007). Clearly, harvesting the sun's immense energy output without the carbon emissions is an obvious solution toward solving this problem.

As the Earth's population grows (potentially reaching 10 billion in $2050^{2}$; Figure 1), so will the demand for energy as well as clean water, food, and other resources. Additionally, less-developed societies continue to modernize bringing the associated benefits to their quality of life such as improved health care, sanitation, food production, housing, education, and economic growth. Both the increasing population and the modernization of societies put stresses onto the Earth's ecosystem and bring a concomitant increase in the total energy consumption (Figure 2) ${ }^{3}$. So how do we anticipate and respond to this upcoming need for more energy and simultaneously work toward sustaining the ecosystem and

${ }^{2}$ http://esa.un.org/unpd/wpp/Excel-Data/population. htm

${ }^{3}$ http://www.eia.gov/countries/data.cfm

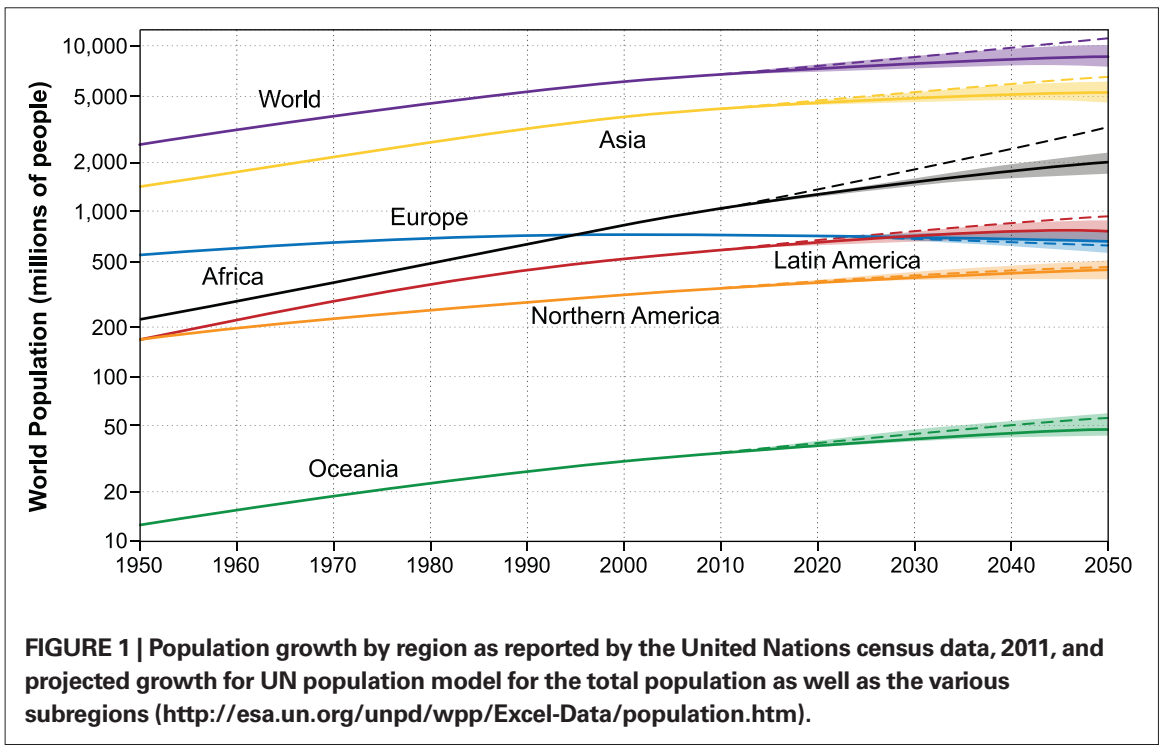




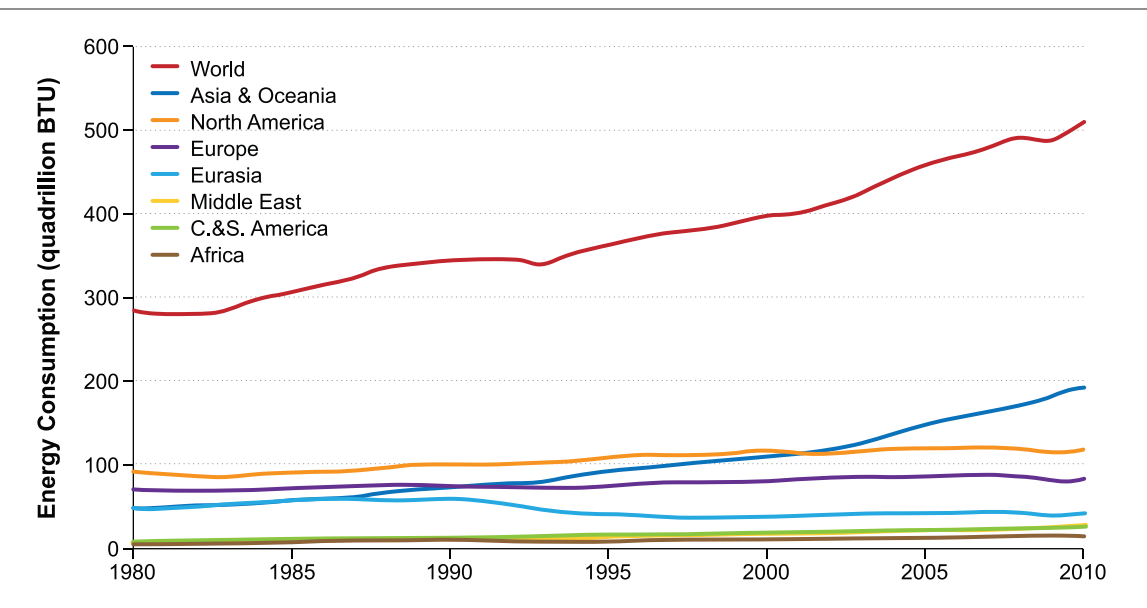

FIGURE 2 |World primary energy consumption in quadrillion Btu (=1055 PJ) from 1980 to 2010 by region according to the U.S. Energy Information Administration. (http://www.eia.gov/countries/data. $\mathrm{cfm})$

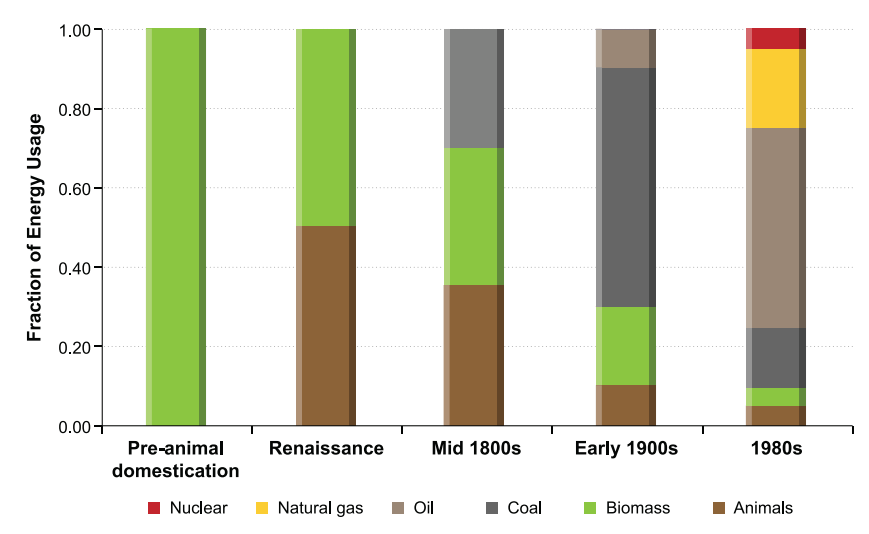

FIGURE 3 | Global energy resources across time for the "Western World" shows how the percentage of energy feedstock changes as new feedstock becomes available (Cahen and Lubomirsky, 2008).

biodiversity, especially while reducing carbon emissions? A wide range of operationally carbon-neutral solutions has been proposed ranging from carbon sequestration for fossil fuels to nuclear power and renewable energy technologies including hydroelectric, photovoltaics, biofuels, concentrating solar power (CSP), wind power, tidal and wave power. Concurrently, we must examine our energy consumption and develop low-emission vehicles and increase the energy efficiencies of all technologies, especially buildings, lighting, and transportation. The potential matrix of technological solutions on both the generation and use sides cannot be applied without carefully considering the social, political, historical, and economic impacts associated with a solution or set of solutions. Indeed, as the world has become more interconnected culturally, technologically, and economically, more and more issues cease to be "local" issues and instead become international or global issues. Pollution or the radiation from a nuclear accident generated in one country does not stop at the border. Global warming and rising sea levels affect all countries with low-lying costal areas. Political instability, warfare, or poverty can cause large shifts in the local populations and cross borders. Countries all vie on the global market for energy resources. These and other concerns mean that some level of cooperation and coordination is needed on a global scale and will determine, in part, the technological solutions that actually come to fruition.

So in this global context, what is the potential for solar energy to make a global impact on energy production, especially electricity production? As discussed above, it is the most abundant energy source avail- able to us and yet the historical precedent and entrenched infrastructure favors fossil fuels. The low areal power density and broad spectral content of the solar resource present a very significant challenge as well in fact, arguably those two challenges drive the necessity for solar energy research and development and hence for the existence of this journal. There do exist current opportunities where the modern energy infrastructure is absent or lacking and solar energy may be a true enabling technology such as for much of the less-developed parts of the planet. The World Bank estimates over 1.2 billion people (about 20\%) of the world population still have no access to electricity ${ }^{4}$. In these situations, often in remote areas away from the electrical grid, solar energy offers a convenient lowmaintenance technology for generating electricity. In addition, 2.8 billion people use wood, charcoal, coal and dung for cooking, heating, and light contributing to 1.5 billion people with a respiratory disease ${ }^{4}$. Solar energy technologies can make a huge impact for these people, but what of the "more developed" world? Figure 3 shows the evolution of energy use in the "Western World" throughout the ages illustrating the progression from biomass to animal power to coal to coal/oil and finally to coal/oil/natural gas/nuclear (Cahen and Lubomirsky, 2008). There are numerous reasons for the impetus for changing the energy source and include technological advances, economics, transportability, dispatchability, energy density, etc. We are beginning to see the shift to renewable energy. Wind energy is one of the fastest growing energy sources for utility-scale electricity generation. The photovoltaic market grew by $80 \%$ in Watts peak produced in 2012 and Si solar-cell technology is approaching or has reached grid parity in many locations. There are many pilot-scale generation plants for solar thermal and solar electrical.

What is unique about the latest trend toward renewable energy is that pollution and global warming are adding to the impetus for change. Pollution has previously been a consideration for change; for example, it has been stated that one of the primary drivers for the automobile was the increasing problems with horse manure as

${ }^{4}$ http://www.worldbank.org/en/topic/energy/ overview 
the population density went up, especially in places like New York City (Morris, 2007). Pollution has also influenced the progression from coal to oil to natural gas. So far this driver, even given global warming, has not been overly effective for renewables. Figure 4 shows the current and projected impact of renewables on the energy mix and indicates that while renewables are growing rapidly, the overall impact of renewables (including hydropower) is not increasing significantly enough to supplant greenhouse-gas-emissions (GhGE) producing technologies at the terawatt level (Conti, 2011). Additionally, the largest current component, "hydropower," is constrained by considerations for water availability, geography, and the politics of transforming the natural habitat. Thus, the real question is why renewable conversion technologies are not on a faster growth curve and are not the "obvious" solution to global energy needs. Clearly, they have not naturally displaced other conventional energy sources though this process is starting. This is a factor of economics, sociology, politics, and technology.

Another key concept and perhaps somewhat unique to this current situation is that the existing infrastructure and business models for the energy supplier marketplace represent the existing paradigm and that must addressed to achieve a financially viable alternative market. For electricity, the business model consists of different "flavors" of electricity (baseline, dispatchable, peak) consumed, bought, and sold among different power districts to meet the instantaneous demand on various timescales. Dispatchable and peak generating facilities are used to match the changing demand, but also electricity is traded over an aging transmission infrastructure that is often near capacity. For renewables to make a significant contribution to actual power consumption, they must be integrated into this market and yet, present an amplified challenge due to the increased complexity of adding variable sources to ever-changing demands. Still, it is expected that the electrical generation system can incorporate renewables up to some level before significant changes to the system itself - such as the integration of massive amounts of storage-become necessary (Conti, 2011). A resistance to any change represents an inertia that must be overcome if renewables are to become a terawatt solution toward reducing GhGE.
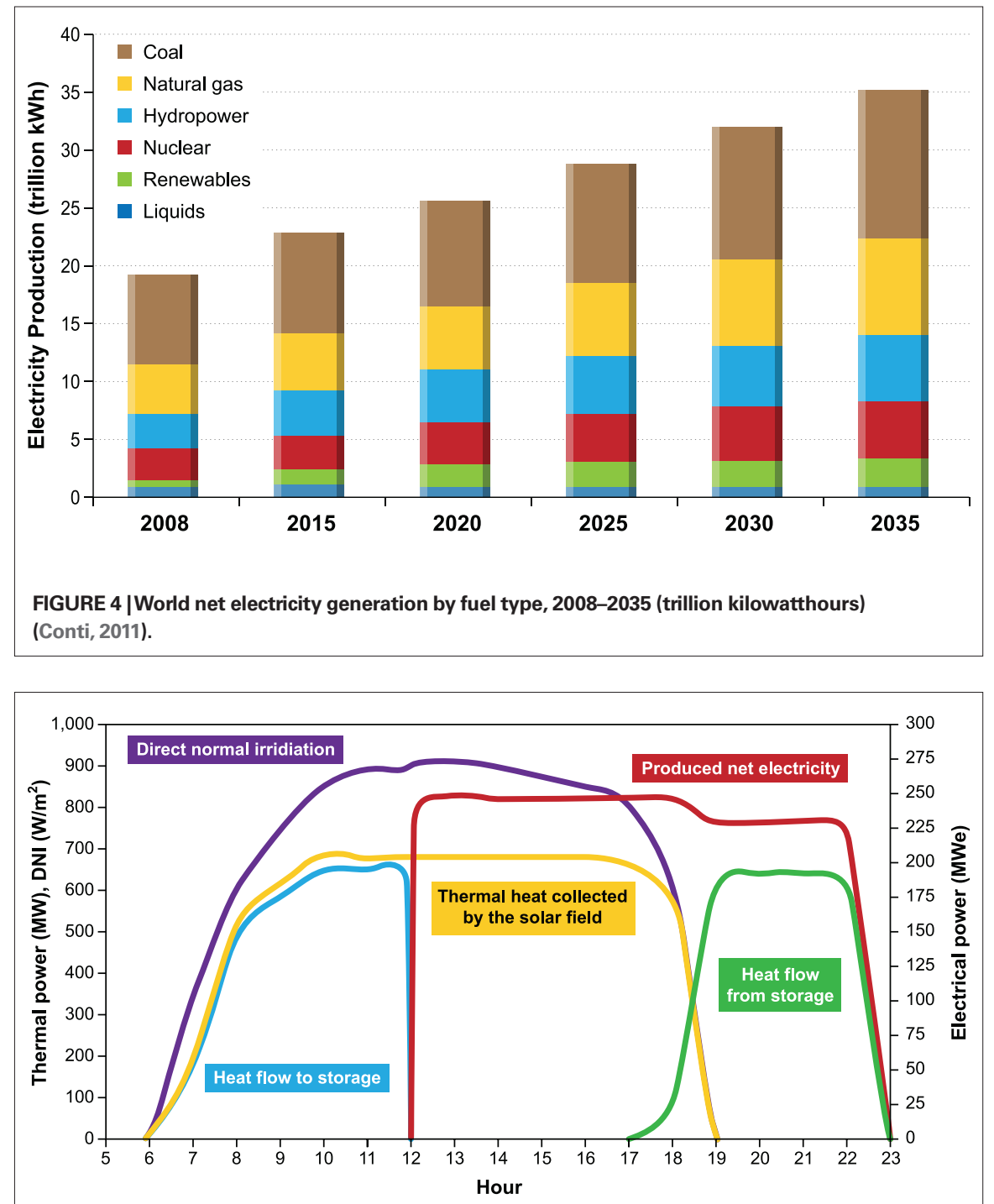

FIGURE 5 |This shows the heat and electricity power components versus time for a CSP facility with thermal energy storage and shows how energy storage can time-shift supply to meet demand (Philibert, 2011).

Energy storage has often been touted as a possible solution to the dispatchability problem, as storage can be used to time-shift supply with demand. This concept is illustrated in Figure 5 that shows the heat and electricity power components versus time for a CSP facility with thermal energy storage (TES) (Philibert, 2011). The heat from the sun can be transferred to a storage tank for use later when the electricity demands are high. Unfortunately, adding a TES capability to a CSP plant adds considerable capital costs to the facility and impacts the levelized cost of electricity (LCOE) for CSP thereby making it difficult to compete with the conventional technologies. Likewise, other storage technologies such as chemical fuels have ongoing technological hurdles, similar cost issues and none yet have any widespread implementation. Only hydroelectric storage facilities have made any inroads, but still only accounts for a very small storage capacity. For storage to become viable, either new cheaper generation/storage technologies must be developed or the cost of conventional generation must increase through other considerations such as mandated pollution control technologies (carbon sequestration) or an outright carbon tax. For energy storage to succeed, low-cost technologies must be 
developed with the ability to store energy at large scale. For remote and isolated "microgrid" systems, storage may be needed at the very outset to time-shift power use to when it is needed. It is also clear that systems integration and life-cycle analysis must be done to fully understand how best to accomplish this integration, i.e., is it at the device, system, or utility level.

An improved transmission grid may also go a long way toward solving the instantaneous supply/demand problem. In this scenario, the transmission grid has enough range, capacity, and efficiency that power can always be delivered from areas that have high electricity production (where the wind is blowing or the sun is shining) to areas that need it. If this concept is taken to the extreme, one could envision a worldwide network where there is always someplace where there is extra capacity being generated. There is general agreement that something must be done to improve this aging infrastructure, but this represents a huge cost in these trying economic times. The bottom line is to understand the cost/benefit analysis, for example, of a long-distance high voltage DC transmission line enabling an increasingly distributed array of renewable resources. An even more advanced concept is the "smart grid" where the utility can anticipate and plan power delivery proactively and where there is still the option to buy and sell capacity with other districts, but more importantly, it can interact with the load components, and there may be some integrated distributed storage as well. For example, the utility may purposely restrict the power delivery to certain areas knowing that the non-critical load components have been designed or programed to react appropriately and without damage. Another example is that during peak loads the utility company may cease the charging of electric vehicles or even draw power back out again under prearranged agreements. Renewable technologies will probably only be truly integrated at large scale when the economics are compelling and the future system grid-level impacts are minimal.

All of these considerations outline the immense task at hand to bring renewable energies to the forefront in electricity generation and distribution. Often, the leading edge in research into new and improved technologies inspires societies to dream about the future and cause that vision to become reality. We focus here on a subset of renewable energy: direct solar conversion technologies. Frontiers in Solar Energy will focus on the research necessary to achieve this vision. This journal will focus on the integrated spectrum of solar energy conversion from new materials to life-cycle and reliability with a connecting theme of the importance of the basic materials and device science. Its scope includes direct energy conversion technologies, e.g., photovoltaics, concentrated solar power, thermoelectrics, and third-generation technologies such as rectennas; materials and device science necessary for large-scale deployment of cost-effective solar technologies; solar light management; active conversion technology; low-cost high-throughput methodologies; life-cycle analysis; environmentally robust packaging with earthabundant materials; and green processing. Overall, its goal is to help change the current trajectory of energy sources (Figure 6) to make solar-based renewables a primary energy source.

Solar can be envisaged as impacting power generation in many applications from small-scale self-powered windows, to building-integrated systems to grid-scale installations. At some level, this comes down to the device technology optimized
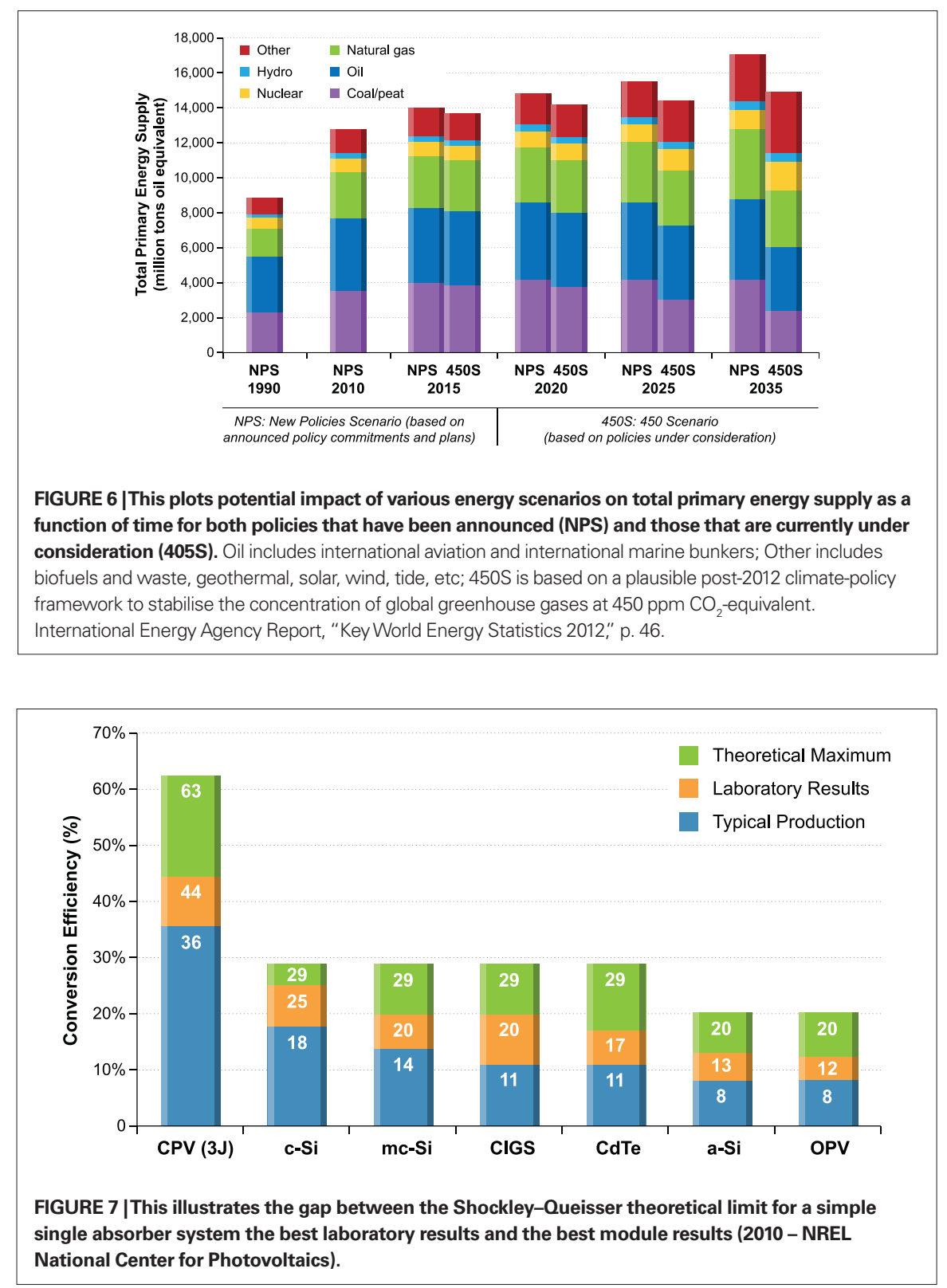
for an application, the system integration of the device (balance of systems) and the ultimate ability to install that application at scale (manufacturing, building codes, etc.). Much work has been done but more remains. Figure 7 shows the plot of theoretical efficiency for photovoltaic cells versus best-cell efficiency versus module efficiency. Clearly, there are significant gains in efficiency possible with every technology, and though improvements are being made over time, there is a need to understand not only the basic materials science, but the device science and the manufacturing science/ engineering of complex systems to be able to drive to higher efficiency at lower cost, which will ultimately make the technology realized. To achieve the improvements needed requires considering all aspects of a solar conversion technology including light management, interface electronic and chemical properties, reliability, and ultimately complete techno-economic and life-cycle analysis. In addition, increasingly hybrid systems are of interest as they can potentially increase efficiency with a small cost increment - for example, this could be tandem thin-film solar cells, the integration of thermoelectrics with solar thermal, and fuel generation with electricity generation. There remains much debate about how much solar energy power generation can be added to the grid without energy storage, but at some point this will become a necessity and systems that utilize hybrid technology may be able to integrate storage as well. We hope that Frontiers in Solar Energy will enable the cross coupling of these various technology areas to help develop an extremely compelling vision for solar energy generation so that its adoption will be a matter of common sense and not a political mandate.

\section{REFERENCES}

Boden, T. A., Marland, G., and Andres, R. J. (2012) Global, Regional, and National Fossil-Fuel CO Emissions. Oak Ridge, TN: Carbon Dioxide Information Analysis Center, Oak Ridge National Laboratory, U.S. Department of Energy. doi: 10.3334/ CDIAC/00001_V2012

Cahen, D., and Lubomirsky, I. (2008). Energy, the global challenge, and materials. Mater. Today (Kidlington) 11, 16-20. doi:10.1016/S1369-7021(08)70248-7

Conti, J. (2011). International Energy Outlook 2011. Washington: U.S. Energy Information Administration.

IPCC. (2007). "Summary for policymakers," in Climate Change 2007: Impacts, Adaptation and Vulnerability. Contribution of Working Group II to the Fourth Assessment Report of the Intergovernmental Panel on Climate Change, eds M. L. Parry, O. F. Canziani, J. P. Palutikof, P. J. van der Linden, and C. E. Hanson (Cambridge: Cambridge University Press), 17.

Lüthi, D., et al. (2008a). EPICA Dome C Ice Core 800KYr Carbon Dioxide Data. IGBP PAGES/World Data Center for Paleoclimatology Data Contribution Series \# 2008055. Boulder CO: NOAA/NCDC Paleoclimatology Program. [Accessed from the Carbon Dioxide Information Analysis Center, Oak Ridge National Laboratory, U.S. Department of Energy].

Lüthi, D., Le, F., Loch, M., Bereiter, B., Blunier, T., Barnola, J. M., et al. (2008b). High-resolution carbon dioxide concentration record 650,000-800,000 years before present. Nature 453, 379-382. doi: 10.1038/ nature06949
Mora, C., Tittensor, D. P., Adl, S., Simpson, A. G. B., and Worm, B. (2011). How many species are there on earth and in the ocean? PLoS Biol. 9:e1001127. doi:10.1371/ journal.pbio.1001127

Morris, E. (2007). From horse power to horsepower. Access 30, 2-9.

Philibert, C. (2011). Renewable Energy Technologies Solar Energy Perspectives. Paris: International Energy Agency.

Rhodes, C. J. (2010). Solar energy: principles and possibilities. Sci. Prog. 93, 37-112. doi:10.3184/0036850 10X12626410325807

Tans, P., and Keeling, R. (2013). Concentrations of CO2 in the Earth's atmosphere (parts per million) derived from in situ air measurements at the Mauna Loa Observatory, Hawaii: Latitude $19.5 \hat{A}^{\circ} \mathrm{N}$ Longitude 155.6 $\hat{A}^{\circ} \mathrm{W}$ Elevation $3397 \mathrm{~m}$. NOAA/ESRL, Scripps Institution of Oceanography. Available at: www.esrl. noaa.gov/gmd/ccgg/trends/; scrippsco2.ucsd.edu/

Tian, Y., and Zhao, C. Y. (2013). A review of solar collectors and thermal energy storage in solar thermal applications. Appl.Energy 104,538-553. doi:10.1016/j. apenergy.2012.11.051

U.S. C. Bureau. (2013). U.S. and World Population Clock. Washington: U.S. Department of Commerce.

Received: 29 July 2013; accepted:26 August 2013; published online: 06 September 2013.

Citation: Ginley DS and Parilla PA (2013) Solar energy: a common-sense vision. Front. Energy Res. 1:3. doi: 10.3389/ fenrg.2013.00003

This article was submitted to Solar Energy, a section of the journal Frontiers in Energy Research.

Copyright (c) 2013 Ginley and Parilla. This is an openaccess article distributed under the terms of the Creative Commons Attribution License (CCBY). The use, distribution or reproduction in other forums is permitted, provided the original author(s) or licensor are credited and that the original publication in this journal is cited, in accordance with accepted academic practice. No use, distribution or reproduction is permitted which does not comply with these terms. 